\section{Literature Review on the Factors Affecting Teaching Effectiveness of Undergraduate Engineering Programmes}

\author{
Sahudin, S. a, Maideen, N.C. ${ }^{b}$, Shamsudin, A.F.a, Shuib, N.A. ${ }^{c}$ \\ a Quest International University, Ipoh, Perak, Malaysia. \\ b Universiti Teknologi MARA, Permatang Pauh, Pulau Pinang, Malaysia. \\ c University Malaysia Perlis, Kangar, Perlis, Malaysia. \\ *shuibbs@gmail.com
}

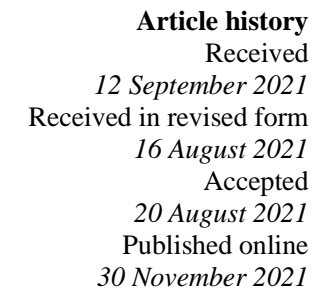

\begin{abstract}
A great deal has been written, over the past three decades, on what constitutes effective teaching in higher education. Teaching effectiveness has been a key concern for universities since it pertains to the achievements of skills required for the competitive job market. The current practice of teaching the engineering fundamental non-culminating courses in undergraduate engineering programmes is through traditional teaching methods. This literature review aims to identify the factors that influence teaching effectiveness of undergraduate engineering programmes. The literature reviewed indicates that researchers have identified lecturers' ability, course characteristics and teaching methods \& material as pertinent measurements of Teaching Effectiveness.
\end{abstract}

Keywords: Teaching effectiveness, lecturers' ability, course characteristics and teaching methods \& materials.

\section{Introduction}

Teaching effectiveness (TE) is a less researched topic in developing countries like Malaysia. It is found, through personal teaching experiences, that final year engineering students lack understanding in integrated design project (IDP) course. Basically, this course is the combination of previous courses. Therefore, if engineering students don't have a strong command on the courses of earlier semesters, it would not be possible for them to understand this IDP course. On the other hand this IDP course is the most important subject for engineering graduates to demonstrate their skills in the job work place. It is a matter of great concern that engineering students lack understanding of this course and it indicates that the problems in previous courses distorted the teaching outcome. Therefore it is necessary to identify the factors that influence the TE of engineering courses. This TE is supposed to influence the employability of our graduates. This situation motivated us, as lecturers who experience this personally, to conduct this study.

Traditionally, teaching means imparting knowledge or skill. It is used interchangeably with pedagogy (Diamond, 2013). A great deal has been written, over the past three decades, on what constitutes effective teaching in higher education (Duarte, 2013). There is some evidence that an understanding of what constitutes effective pedagogy - the method and practice of teaching - may not be so widely shared, and even where it is widely shared it may not actually be right (Hamre et al., 2009; Strong et al., 2011). Hence, it is necessary to clarify what is effective pedagogy. What are the significant factors of $\mathrm{TE}$ in undergraduate engineering programmes? This literature review explores the factors affecting TE in undergraduate engineering programmes.

The current practice of teaching the engineering fundamental non-culminating courses in undergraduate engineering programmes is through traditional teaching methods. According to Kiymet Selvi (2012), while the creation and construction of knowledge must be the main issues in the learningteaching process, creating and constructing knowledge cannot be the primary aims for them in the typical formal learning-teaching system. Students and teachers don't have sufficient time to create and construct knowledge in the formal learning-teaching process, so teachers mostly transmit and distribute ready-made knowledge in this process. In the formal learning-teaching system, students must follow their teachers' plans and other education policy-makers who decide what type of knowledge and experiences are important for students' learning. Engineering programmes are a coherent set of taught elements, courses or modules which leads to a qualification such as a degree. Programmes which lead to a first degree such as BEng, BSc or BS are called undergraduate programmes (Goodhew, 2010).

A proper understanding of TE is a vital factor for any educational institution. From this study, engineering lecturers can ascertain where the attention needs to be given for planning and implementing the right knowledge and teaching practices. Academicians can impart the knowledge content and skills generated from this review among the learners who might materialize it in their practical field. A great concern regarding the issue of TE is the specific constructs that influences TE. The findings of this review will add new dimensions in the literature relating to $\mathrm{TE}$. 


\section{Literature Review}

For many years, teaching effectiveness (TE) at higher education institutions has been the focus of many researchers (Cohen, 1981; Lewis et al., 1988; Mukherji \& Rustagi, 2008). Traditionally, teaching means imparting knowledge or skill. Effective means efficient or successfully producing desired result or outcome. In order to determine the determinant factors affecting TE, one must first arrive at a comprehensive definition of teaching effectiveness. TE encompasses imparting relevant knowledge \& skills efficiently or successfully to the point where students have mastered the subject or courses taught (Van der Marwe, 2012). TE also judges whether studies provide credible evidence of positive student outcomes (including knowledge, skills, attitudes, and values) linked to particular practices. In addition to examining student achievement, other factors such as student motivation, interest in subject matter and career aspirations can be impacted by teaching (StarkWroblewski et al., 2007).

For the teaching characteristics of engineering colleges, TE is connoted as follow: effective teaching is teaching activities the teacher applies, at the optimal speed, effectively and efficiently to encourage or allow the students to achieve "three dimensions objectives", encompassing (i) knowledge and skills, (ii) process and methods, and (iii) attitudes and values. All while sustaining progress and development in order for the student to meet the education standards of the society and the students' own personal needs. Several past studies found that students' evaluation of teaching effectiveness (SET) offers a reliable and valid assessment of teaching (Hooper \& Page, 1986; American Accounting Association, 1988; Cranton \& Smith, 1990; Holtfreter, 1991; Toby, 1993). In fact, SET is one of the most commonly used teaching evaluation methods in universities worldwide (Newton, 1988; Seldin, 1989; Stratton, 1990).

TE can be measured by how much students learn within a given class. The student learning method is used infrequently. Despite the limitations and difficulty inherent in the measurement of student learning, some researchers have found that this method is reliable and valid. Student evaluations of teaching instruction are the most commonly used and easiest to assess in university settings, despite opposition from instructors who argue that students' ratings are popularity contests (Al-Issa \& Sulieman, 2015). Overall, student ratings appeared to be a reliable and valid measure of TE (Kogan \& Schoenfeld-Tacher, 2010).

\section{Determinant Factors Affecting TE}

Although student evaluations have become the primary tool used to evaluate the TE of their faculty (Seldin, 1993), Simpson (1995) found that student evaluations were the most consistent and most controversial source of information used to evaluate TE. Despite some dissent among higher education professionals, a large body of research evidence indicates that student evaluation of teaching is valid. This opinion is partly based on evidence from the research showing a positive correlation between student evaluations of faculty members and objective measures of student achievements (Yunker \& Yunker, 2003).

Green et al. (1999) found that students are able to reliably evaluate effectiveness of teaching and that student evaluations are a valid tool for measuring teaching ability. Cohen (1981) also suggests that student evaluations are generally valid and reliable and serve as good predictors of how much students actually learn in class and consequently are used as a primary information source in evaluating TE (Green et al., 1998). Amin (2002) is of the opinion that the results of student evaluations may help the lecturers to improve upon their teaching strategies; it may help students in the choice of their courses and it could be useful to administrators in their decisions concerning promotion appointments and renewal of lecturing contracts.

Frey (1973, 1974, and 1978) and others have strongly argued for including only the individual teaching dimensions to the exclusion of global rating attributes which he demonstrated in a measure developed by him which he called as "Endeavor." Marsh and Dunkin (1992) take a middle path between the positions adopted by Abrami et al. (1997), wherein they recommend using attributes of both individual teaching dimensions and global ratings. Ryan and Harrison (1995) recommend that three types of student rating information should be used in making personnel decisions: individual teaching dimension ratings; overall evaluations made by students; and a composite weighted average indicating an overall evaluation score. Burdsal and Harrison (2008) in their study provide empirical evidence supporting the use of both multidimensional scale and an overall evaluation for determining TE, as valid indicators of student perceptions of effective classroom instruction. According to Shevlin et al. (2000) students may be systematically influenced by teachers' traits (such as "charisma") and give higher ratings to their teachers irrespective of their actual TE. They cite theories of personality (Asch, 1946; Bruner et al., 1958) and research evidence, which shows that manipulation of bipolar attributes such as warm-cold (Kelley, 1950) significantly impact students' judgment of their teachers. So, student perceptions of a single attribute may influence judgments' of the individual teacher across various dimensions (Vernon, 1964).

There is ambiguity on whether the determinant variables being measured are dominant because they are measurable. It is also unclear how much the dimensions of Student Evaluation of Teaching Effectiveness (SET) can influence TE construct (Abrami et al., 1997; Marsh \& Roche, 1997).

Hamid and Pihie (2004) stated that service quality factors in teaching comprised five (5) measures: (i) Lecturer factor, (ii) Teaching methodology, (iii) Course 
relevance, (iv) Facilities, and (v) Support services. However, Hamid and Pihie (2004) conducted analysis on the quality of teaching using only the measures for Lecturer factor, Teaching methodology, and Course relevance because these three were the only dominant factors assumed to be directly under the control or influence of the Faculty and lecturers.

\section{Lecturer's Ability}

Lecturer's Ability refers to the capability of the instructors to teach effectively so that the best teaching outcome is achieved. It is often used interchangeably with Teaching Ability. Educators believe that the act of teaching creates an intimate and inseparable relationship between teacher and student (Ovando, 1989). This symbiotic relationship must be considered an important element in the process of evaluating and improving instruction in higher education, especially since the ultimate result of effectiveness of teaching is student learning and their mastering of the content of specific courses. Therefore, students' feedback and perceptions of teaching should play a role in improving the quality of education (Van der Marwe, 2012; Mart, 2017; Serin, 2019). Evaluating a faculty member's teaching ability is one of the most difficult and contentious tasks faced by administrators. Although teaching ability is regarded one of the primary factors in promotion and tenure decisions, there is little agreement on how TE should be measured (Lewis et al., 1988; Mukherji \& Rustagi, 2008).

At the heart of TE is the teacher's ability to understand the individual profiles (i.e. the strengths and weaknesses) of every student in the classroom. Based on these factors, teachers can then adjust the instructional intensity necessary in order to meet the academic goals (Elizabeth, 2013). For those students working at or above grade-level, the teacher can extend the academic goals to encourage students to reach higher levels of achievement. Most importantly, the teacher can set his or her instructional priorities and manage available time and resources to help the students who are in greatest need. The teacher provides whole-group instruction on the particular concept, and then gives students the opportunity to practice that particular skill or concept through peer discussions, independent center activities or homework assignments. Graded homework assignments and subsequent curriculum based tests (such as an end-of-unit quiz) helps the teacher understand which students may be struggling and require further instruction (Elizabeth, 2013). So, lecturers' ability is very important for teaching effectiveness.

Traditionally, lecturers are evaluated according to three major criteria: teaching, research, and services. While research and services are evaluated by departmental and university committees, TE is evaluated by the students. Student evaluations are the primary tool used by administrators to evaluate TE (Yunker \& Sterner, 1988; Mart, 2017; Serin, 2019).
Teaching is multidimensional in nature and there are many possible indicators of effectiveness of teaching. The procedures for developing and using student evaluation instruments have varied considerably. Faculties often argue that TE is difficult to identify and nearly impossible to validly measure, so individual faculty members should be allowed to use subjective judgment to determine how to conduct their classes (Simpson, 1995). However, since TE is one of the primary factors used in promotions and tenure decisions, faculty members and administrators need to agree on a valid method to evaluate teaching ability.

Wei Hong and Shen Jiliang (2002) required students to evaluate the teaching of the teachers according to the teaching evaluation table. The results through their empirical study show that (the teacher's characteristics in effective teaching) the students' ability improved by the teacher's teaching, clear expression by the teacher, distinctive teaching style and characteristic of the teacher, teachers responsible for teaching and difficult contents prominently, and the teachers ability to stimulate the students' interest and initiative.

Mixed results were reported on the association between student evaluation results and course level or division (Liaw \& Goh, 2003; Green et al., 1998). Instructors teaching at higher levels often received better student evaluation ratings, presumably because higher level students, while being more motivated in their studies, are also more discriminating in their evaluations (Langbein, 1994; Holtfreter, 1991; Aleamoni \& Hexner, 1980; Cashin, 1989; Shapiro, 1991). Others have shown that instructors of different levels of courses received relatively different ratings (Cranton \& Smith, 1986; Koh \& Tan, 1997). Most research reports no differences between faculty evaluations given by students in graduate and undergraduate courses (Gage, 1961; Goldberg \& Callahan, 1991). However, some studies (i.e. Boex, 2000; Whitworth et al., 2002) noticed that graduate students did evaluate faculty members more favorably than undergraduate students. Mulford and Schneider (1988) found no significant differences between the mean ratings of instructors teaching undergraduate and graduate courses.

Smith (1995) stated that in education, teachers are the main resource of creating high-quality opportunities for the students. Sometimes teachers do good things and do bad things. Teachers should have the understanding of what they are to do and are ready to share all this will have an effect on students. According to Bates (2012), great communication between students and teachers are the building blocks of the best educational relationship that a teacher and student should have. The good instructors are noted by how they explain information to their students. How well they provide feedback to allow ideas to be expressed freely and actively ask questions between learner and educator. And with the advent of the latest technology in education, teachers can promote themselves as modern educators. They can connect 
positively to students every time and at varied ways. According to Ihmeidah et al. (2010), teachers are collecting, sorting, analyzing and explaining information to students. Teachers should have good communication skills to be successful in their jobs. Teachers need listening, interpersonal, written and oral communication skills to facilitate teaching. The outcome of the attitudes toward communication skills can make both teachers and their students be more prepared for their classroom environment and improving effective communication.

Ismail et al. (2018) breaks down Lecturer's ability into seven aspects: organization, speech-pacing, clarity, enthusiasm, interaction, rapport, and disclosure. It was found that the most highly rated aspects were organization and speech-pacing.

Robert Coe et al. (2014) suggest that teachers should consider Pedagogical Content Knowledge when assessing teaching quality, as strong evidence shows that focusing on these components can improve student outcomes. The very best teachers are those that demonstrate pedagogical content knowledge. The most effective teachers have deep knowledge of the subjects they teach, and when teachers' knowledge falls below a certain level it is a significant impediment to students' learning. As well as a strong understanding of the material being taught, teachers must also understand the ways students think about the content, be able to evaluate the thinking behind students' own methods, and identify students' common misconceptions. Dardiri (2017) found that there was no correlation between work environment and teacher performance, meaning that the work environment (conditions of physical work environment, psychological work environment, and non-physical work environment) does not positively support the pedagogical and professional performance of teachers.

In summary, the literature reviewed indicates that lecturer's ability is a valid measure of TE. Therefore, whether the Lecturers' ability influences TE or not, should be investigated further.

\section{Course Characteristics}

The course content, service given by the lecturers and the faculty, course assessment, instruction medium, social activities, concern for students and facilities constitute the course characteristics of a programme (Peng \& Samah, 2006). The course characteristics are related to academic program given to students (Le Blanc \& Nguyen, 1997; Kwek et al., 2010). Considerable evidence exists that the subject matter of a course affects students' evaluation of teaching effectiveness (SET) (Neumann \& Neumann, 1983; DeBerg \& Wilson, 1990; Cho \& Baek, 2019). Some authors suggested that the nature of the subject might explain the variation in SET results (Clark, 1993; DeBerg \& Wilson, 1990; Cranton \& Smith, 1986; Langbein, 1994).

The assessment dimension of teaching is related to the standards and academic assessment system applied by the university (Peng \& Samah, 2006). Academic score for formal educational institutions is an outcome indicator of the success of an educational program (Sang, 2007). Achievement of a university student is generally measured by his or her academic score or grade point average (GPA). Research by Lagrosen et al. (2004) shows that internal evaluation, including course evaluation, is one of student perceived service quality which denotes the teaching outcome. Hence the course characteristics are being used as a standard measure for teaching effectiveness. Lizzio et al. (2002), proposed good teaching, clear goals and standards, appropriate workload, appropriate assessment, emphasis on independence and generic skills, and an overall satisfaction item that can be used as a simple means for the criterion-related validity checking of these scales.

The course characteristics should clearly portrait learning objectives, assessment and instructional strategies (Fink, 2003). There should have a clear guideline of what course structure should be; finding strategy of teaching to approach learning goals and setting schedule. The course characteristics also imply the syllabus which is a guideline and summary topics of the course study. A syllabus shows information about the course schedule, test dates, due dates for assignment, the policy for grading of the subject, specific classroom rules and etc. As in many courses it concludes in the exam. From syllabuses it is guaranteed that all teachers should have the knowledge of what must be taught and what are not to be taught. Test papers can only measure knowledge based on what is learned that are in the syllabus. Good syllabus should show what students will do and learn, and what they can expect. It guides student learning with the expectations and decreases the number of problems in the course. According to Patricia (2008) the course characteristics have a positive effect on teaching outcome as it is a written agreement, even if it is not in the legally recognized. It shows expectations about the course and tasks early in the semester.

In many articles, curriculum is also known as course content (Kwek et al., 2010; Peng \& Samah, 2006; Mart, 2017), subject content (Athiyaman, 1997), program issues (Ford et al., 1999), and academic concerns (Russel, 2005). Several articles show that curriculum is overall student perceived outcome determinant (Athiyaman, 1997; Sohail \& Shaikh, 2004). Other research shows that curriculum has a positive relationship with overall student perceived quality or teaching outcome (Le Blanc \& Nguyen, 1997; Kwek et al., 2010). Previous literature indicates that curriculum has a positive influence on overall student perceived service quality, and was referred to as a student perceived service quality determinant (Athiyaman, 1997; Sohail \& Shaikh, 2004). The assessment system also has a positive significant effect on overall teaching outcome. This means that any improvement in the assessment dimension will result in improved perceived service quality. Thus, the assessment system is also an important issue for 
making teaching effective and its importance is increasing.

In summary, the literature reviewed indicates that course characteristics is a valid measure of TE. Therefore, whether the course characteristics influences TE effectiveness or not, should be investigated further.

\section{Teaching Methods \& Materials}

The teaching methods \& materials (TM) are related to the way of imparting knowledge and physical facilities that support both academic and nonacademic activities (Joseph et al., 2005; Peng \& Samah, 2006; Kwek et al., 2010; Ko et al., 2014). In several articles, this dimension is also referred as tangibles (Soutar \& McNeil, 1996; Cuthbert, 1996; Pariseau \& McDaniel, 1997; Ham \& Hayduk, 2003; Abu Hasan et al., 2008), physical evidence (Sohail \& Shaikh, 2004), and physical aspects (Ford et al., 1999). Some other researchers alter these dimensions to some specific dimensions, such as computing facilities (Hill, 1995; Athiyaman, 1997) and recreational facilities (Athiyaman, 1997). A study by Joseph et al. (2005) surveyed 450 students of a small liberal arts university in the US shows that facilities - by using ImportancePerformance analysis methods - are located in "concentrate here" quadrant. The literature shows that facilities are considered important from a student's perspective. Le Blanc \& Nguyen (1997) stated that teaching methods \& materials have a positive and significant impact on overall student perceived quality.

Universities all over the world are using teaching methods \& materials (TM) as ways to increase teaching outcome. Their teaching methods \& material include both academic and extra curriculum activities that include teaching and student involvement in curriculum; joint consultation; work expertise placements, computing facilities, library service, university bookshop, careers service; counseling welfare; financial service; health service; accommodation services, students' union; catering service; physical education and travel agency (Hill, 1995). Athiyaman (1997) also mentioned that teaching capability, staff availability, library service, computing facilities; class sizes, subject content, student workload and recreational facilities might bring forth better teaching outcome of university graduates. On the other hand, Lagrosen et al. (2004) stated that teaching outcome can be increased by corporate collaboration, information and analysis, courses offered, internal evaluations, computer facilities, collaboration and comparisons and finally library resources.

The medium of instruction dimension related to teaching, learning and assignment activities is also an important factor for making teaching effective (Peng \& Samah, 2006). The instruction medium has a positive significant effect on perceived service quality of graduates. The instruction medium dimension is related to the use of language in academic activities. This dimension is important because students generally hope to work in a multinational company, where English is a prerequisite. In a developing countries context, the capability of speaking English for the student provides added value, as it is not their native language. Russell (2005) argued that teaching and learning activities using English is a factor considered by the student in choosing a university. Furthermore, Peng \& Samah (2006) also found that the instruction medium dimension is a student perceived quality determinant and significantly influences teaching outcome. Therefore universities should provide sufficient academic and non-academic supports to increase the teaching outcome.

Research suggest that teachers should consider quality of instruction when assessing teaching quality, as strong evidence shows that focusing on this components can improve student outcomes (Robert Coe et al., 2014; Cho \& Baek, 2019). The very best teachers are those that demonstrate quality of instruction which includes elements such as effective questioning and use of assessment by teachers. Specific practices, like reviewing previous learning, providing model responses for students, giving adequate time for practice to embed skills securely and progressively introducing new learning (scaffolding) are also elements of high quality instruction.

In summary, the literature review indicates that teaching methods \& material is a valid measure of TE. Therefore, whether the teaching methods \& material influences TE effectiveness or not, should be investigated further.

As an overall summary, the literature review indicated that researchers have identified lecturers' ability (Yunker \& Yunker, 2003; Wei Hong \& Shen, 2009; Bates, 2012; Elizabeth, 2013), course characteristics (Athiyaman, 1997; Le Blanc \& Nguyen, 1997; Sohail \& Shaikh, 2004; Kwek et al., 2010) and teaching methods \& material (Lizzio et al., 2002; Sang, 2007) as pertinent measurements of Teaching Effectiveness.

\section{Discussion and Conclusion}

Universities should design the courses or programs in a way so that students can achieve the required skills necessary for the competitive job market. For this reason TE has become a key issue for the educational institutions. Through extensive literature review lecturers' ability, teaching methods \& materials and course characteristics were found to be determinants of TE. Future studies could be recommended to determine which among the determinants are the most important factors.

Lecturers are the ones who might exhort great influence on their students. This is due to the fact that lecturers have direct contact with the students. Literature reviewed indicates that lecturers' ability is a significant factor that ensures TE. If the lecturers have strong command on their subject knowledge and they are good enough to make things clear to the students, it would surely yield better teaching outcome which is 
the expectation of both graduates and employers. Better teaching outcome also increases the chances of graduates' employability. Therefore, universities should emphasize on the lecturers' ability to ensure teaching effectiveness.

Course characteristics obviously influence the learning process of the university students. The course content, service given by the lecturers and the faculty, course assessment, instruction medium, concern for students and facilities constitute the course characteristics of the program (Peng \& Samah, 2006). Educational researchers think that course characteristics are important issues to the success of any teaching programs (Lagrosen et al., 2004). The literature reviewed indicates that course characteristics are significantly related to teaching effectiveness. It implies that TE can be gained by providing the students a clear guideline of course structures, specific strategies of teaching to achieve learning goals and setting proper schedule. From the beginning of the courses, students should be given the syllabus which is a guideline of information about the course schedule, test dates, due dates for assignment, the policy for grading of the subject, specific classroom rules and etc. If they get this earlier in the semester, it will help them to make plans for the whole academic semester. This clear guideline regarding the courses might help the students to grasp the comprehensive knowledge of a particular subject. Hence universities should put forth efforts to develop an effective course curriculum and provide it to the students so that the best teaching outcome can be achieved.

Teaching methods \& materials also play an important role in imparting knowledge to university students. The process of teaching and physical facilities that support both academic and non-academic activities are expected to generate positive effect on teaching outcome (Joseph et al., 2005; Peng \& Samah, 2006; Kwek et al., 2010). The literature reveals that teaching methods \& materials are correlated to teaching effectiveness. This calls for the enhancement of academic and non-academic facilities like physical evidence, computing facilities, joint consultation, work expertise placements, library service, university bookshop, careers service, counseling welfare, financial service, health service, accommodation services, students' union; catering service, physical education staff availability, class sizes, and recreational facilities which might bring forth better teaching outcome of university graduates.

In summary, the literature reviewed indicates that researchers have identified lecturers' ability (Yunker \& Yunker, 2003; Wei Hong \& Shen, 2009; Bates, 2012; Elizabeth, 2013), course characteristics (Athiyaman, 1997; Le Blanc \& Nguyen, 1997; Sohail \& Shaikh, 2004; Kwek et al., 2010; Cho \& Baek, 2019) and teaching methods \& material (Lizzio et al., 2002; Sang, 2007; Cho \& Baek, 2019) as pertinent measurements of TE.

Future study could be recommended to add new knowledge in the body of literature regarding determinants of $\mathrm{TE}$ and graduates employability.
There is a debate in literature about the generalizability of the structure and the validity of the measures of student evaluation of teaching effectiveness (SET). A great concern regarding the issue of TE is the specific constructs that influences TE. Future study could be recommended to address this issue by investigating the influence of lecturers' ability, course characteristics and teaching methods \& materials on TE. Findings of future study could add new dimensions in the literature relating to TE. Future study findings could determine whether lecturers' ability, course characteristics and teaching methods \& materials are strong predictors of TE.

Previously researchers only focused on developing and validating the measures of TE; but issues relating to the specific constructs that might influence TE still remained unaddressed. There is still lack of consensus about the number of dimensions that constitute TE and to what extent TE is influenced by the existing factors (Abrami et al., 1997; Marsh \& Roche, 1997). Future study could provide strong support for all these gaps by exploring the significant predictors of TE.

\section{References}

Abrami, P.C., D’Apollonia, S. \& Rosenfield, S. (1997). The dimensionality of student ratings of instruction: what we know and what we do not, in Perry, R.P. and Smart, J.C. (Eds), Effective Teaching in Higher Education: Research and Practice, Agathon Press, New York, NY, pp. 321-367.

Abu Hasan, H.F.A., Ilias, A. \& Rahman, R.A. (2008). Service quality and student satisfaction: a case study at private higher education institutions, International Business Research, 1 (3), pp. 163-75.

Al-Issa, Ahmad \& Sulieman, Hana (2015) Student Evaluations of Teaching: Perceptions and Biasing Factors. Quality Assurance in Education 15 (3), pp. 302-317

Aleamoni, L. \& Hexner, P. (1980). A review of the research on student evaluation and a report of the effect of different sets of instructions on student course and instructor evaluation, Instructional Science, Vol. 9, pp. 67-84.

American Accounting Association (1988). A Framework for the Development of Accounting Education Research, American Accounting Association, Sarasota, FL.

Amin, T.G. (2002). A functional linguistic approach to concepts and concept learning in science. Doctoral Dissertation, Department of Psychology, Clark University, Worcester, MA, USA.

Asch, S.E. (1946). Forming impressions of personality, Journal of Abnormal and Social Psychology, 41 (2), pp. 258-290.

Athiyaman, A. (1997). Linking student satisfaction and service quality perceptions: the case of university education, European Journal of Marketing, 31 (7), pp. 528-40.

Bates, L. (2012). Ten Great Tools for Student-Teacher Communication.

Boex, L. (2000). Attributes of effective economics instructors: an analysis of student evaluations, Journal of Economic Education, Summer, pp. 211-27.

Bruner, J. S., Shapiro, D. \& Tagiuri, R. (1958). The meaning of traits in isolation and combination. In R. Tagiuri \& L. Petrullo (Eds.), Person perception and interpersonal behavior (pp. 277-288). Stanford, CA: Stanford University Press.

Burdsal, C.A. \& Harrison, P.D. (2008). Further evidence supporting the validity of both a multidimensional profile and an overall evaluation of teaching effectiveness, 
Assessment and Evaluation in Higher Education, 33 (5), pp. 567-576.

Cashin, W.E. (1989). Defining and evaluating college teaching, Paper No. 21, IDEA, Kansas State University Center for Faculty Evaluation and Development, Manhattan, KS.

Cho, J. \& Baek, W. (2019). Identifying Factors Affecting the Quality of Teaching in Basic Science Education: Physics, Biological Sciences, Mathematics, and Chemistry. Sustainability. 11, 3958.

Clark, D. (1993). Teacher evaluation: a review of the literature with implications for educators, Seminar in Elementary Education, California State University at Long Beach, Long Beach, CA, Spring.

Cohen, P. (1981). Student ratings of instruction and student achievements, a meta-analysis of multisection validity studies. Review of Education Research, 51 (Fall, 1081), 281-309.

Cranton, P. \& Smith, R.A. (1986). A new look at the effect of course characteristics on student ratings of instruction, American Educational Research Journal, Spring, pp. 11728.

Cranton, P. \& Smith, R.A. (1990). Reconsidering the unit of analysis: a model of student ratings of instruction, Journal of Educational Psychology, 82 (2), pp. 207-12.

Cuthbert, P.F. (1996). Managing service quality in Higher Education: is SERVQUAL the answer? Part 2. Managing Service Quality, 6 (3), 31-35.

Dardiri A. (2017) Teacher performance and work environment in the instructional process in vocational school. Green Construction \& Engineering Education For Sustainable Future: Proceedings of the Green Construction \& Engineering Education (GCEE) Conference 2017

DeBerg, C.L. \& Wilson, J.R. (1990). An empirical investigation of the potential confounding variables in student evaluation of teaching, Journal of Accounting Education, 8 (1), pp. 37 62.

Diamond, I. (2013). Effective Learning \& Teaching in UK Higher Education (The Higher Education Academy), Page 14-17. Professor Sir Ian Diamond, speaking at the 2nd Annual UUK Conference on Efficiency, 26 February 2013. London: Universities UK.

Duarte, F.P. (2013). Conceptions of Good Teaching by Good Teachers: Case Study from an Australian University

Elizabeth Brooke (2013). Empowering Teacher Effectiveness: Five Key Factors for Success. Vice President of Education and Research, Lexia Learning.

Fathi M. Ihmeidah, Aieman Ahmad Al-Omari \& Khloud A. AlDababneh (2010). Attitudes toward Communication Skills among Students'-Teachers' in Jordanian Public Universities, Australian Journal of Teacher Education: 35 (4), Article 1.

Fink, L.D. (2003). Creating significant learning experiences: An integrated approach to designing college courses. San Francisco: CA: John Wiley \& Sons, Inc.

Ford, J.B., Joseph, M. \& Joseph, B. (1999) Importanceperformance analysis as a strategic tool for service marketers: the case of service quality perceptions of business students in New Zealand and the USA, The Journal of Services Marketing, 13 (2), pp. 171-86.

Frey, P.W. (1973). Student ratings of teaching: validity of several rating factors, Science, 182 (4107), pp. 83-85.

Frey, P.W. (1974). The ongoing debate: student evaluation of teaching, Change, 6 (1), pp. 47-49.

Frey, P.W. (1978). A two-dimensional analysis of student ratings of instruction, Research in Higher Education, 9 (1), pp. 6991.

Gage, N.L. (1961). The appraisal of college teaching. Journal of Higher Education. 32.17-22.

Goldberg, G. \& Callahan, J. (1991). Objectivity of student evaluations of instructors. Journal of Education for Business. 66 (6), 377-378.
Green, B., Calderon, T. \& Reider, B. (1998). A content analysis of teaching evaluation instruments used in accounting departments, Issues in Accounting Education, 13 (1), pp. 15-30.

Green, B.P., Calderon, T.G., Gabbin, A.L. \& Habegger, J.W. (1999). Perspectives on Implementing a Framework for Evaluating Effective Teaching. Journal of Accounting, 17 (1)

Ham, L. \& Hayduk, S. (2003). Gaining competitive advantages in higher education: analyzing the gap between expectations and perceptions of service quality. International Journal of Value-Based Management, 16 (3), 223-242.

Hamid, J.A. \& Pihie, Z.A.L. (2004). Students' Perception of the Quality of Teaching and Learning in Business Studies Programs. Pertanika J. Soc. Sci. \& Hum. 12 (1): 71-86

Hamre, B.K., Goffin, S.G. \& Kraft-Sayre, M. (2009). Classroom Assessment Scoring System Implementation Guide: Measuring and Improving Classroom Interactions in Early Classroom Settings.

Hill, F.M. (1995). Managing service quality in higher education: the role of the student as primary consumer, Quality Assurance in Education, 3 (3), pp. 10-21.

Holtfreter, R.E. (1991). Student rating biases: are faculty fears justified? The Woman CPA, Fall, pp. 59-62.

Hooper, P. \& Page, J. (1986) Measuring teaching effectiveness by student evaluation, Issues in Accounting Education, Spring, pp. 56-64.

Ismail MA-A, Mohd Fakri NMR, Mohammad JA-M, Mat Nor MZ, Ahmad A, Yusoff MSB (2018). Teaching effectiveness during lectures in Universiti Sains Malaysia School of Medical Sciences. Education in Medicine Journal. 10 (3): 13-22.

Joseph, M., Yakhou, M. \& Stone, G. (2005). An educational institution's quest for service quality: customers' perspective. Quality Assurance in Education 13(1): 66-82.

Kelley, H.H. (1950). The warm-cold variable in first impressions of persons, Journal of Personality and Social Psychology, 18 (3), pp. 431-439.

Kiymet Selvi (2012). Creation and Construction of Knowledge in Learning-Teaching Process. In Phenomenology and the Human Positioning in the Cosmos. pp. 167-179

Ko J., Sammons P. \& Bakkum L. (2014). Effective Teaching. Education Development Trust.

Kogan, Lori R., Schoenfeld-Tacher, R. \& Hellyer, Peter W. (2010) Student Evaluations of Teaching: Perceptions of Faculty Based on gender, position, and rank. Teaching in Higher Education 15 (6), pp. 623-636

Koh, H. \& Tan, T. (1997). Empirical investigation of the factors affecting SET results, International Journal of Educational Management, 11 (4), pp. 170-8.

Kwek Choon Ling, Lau Teck Chai \& Tan Hoi Piew (2010) The inside-out' and 'outside-in' approaches on students' perceived service quality: an empirical evaluation, Management Science and Engineering, 4 (2), pp. 1-26.

Lagrosen, S., Seyyed-Hashemi, R. \& Leitner, M. (2004) Examination of the dimensions of quality in higher education, Quality Assurance in Education, 12 (2), pp. 619.

Langbein, L.I. (1994). The validity of student evaluations of teaching. Political Science and Politics, September, 1994

Le Blanc, G. \& Nguyen, N. (1997). Searching for excellence in business education: an exploratory study of customer impressions of service quality, International Journal of Educational Management, 11 (2), pp. 72-9.

Lewis, K.G., Woodward, P. \& Bell, J. (1988). Teaching business communication skills in large classes. Journal of Business Communication, 25 (1), 65-86.

Liaw, S. \& Goh, K. (2003). Evidence and control of biases in student evaluations of teaching, The International Journal of Educational Management, 17 (1), pp. 37-43. 
Lizzio, A., Wilson, K. \& Simons, R. (2002). University students' perceptions of the learning environment and academic outcomes: implications for theory and practice, Studies in Higher Education, 27 (1), pp. 27-52.

Marsh, H.W. \& Dunkin, M. (1992). Students' evaluations of university teaching: A multidimensional perspective, in Smart, J.C. (Ed.), Higher Education: Handbook on Theory and Research, Vol. 8, Agathon Press, New York, NY, pp. 143-234.

Marsh, H.W. \& Roche, L.A. (1997). Making students' evaluations of teaching effectiveness effective. American Psychologist, 1997, (52) pp. 1187-1197.

Mart, C.T. (2017). Student Evaluations of Teaching Effectiveness in Higher Education. International Journal of Academic Research in Business and Social Sciences, 7 (10), pp. 57-60

Mukherji, S. \& Rustagi, N. (2008). Teaching evaluations: Perceptions of students and faculty. Journal of College Teaching \& Learning, 5 (9), 45-54.

Mulford, C. \& Schneider, A. (1988). An empirical study of structural and controllable factors affecting faculty evaluations, Advances in Accounting, Vol. 6, pp. 205-15.

Neumann, Y. \& Neumann, L. (1983). Characteristics of academic areas and students' evaluation of instruction, Research in Higher Education, pp. 323-334.

Newton, J. (1988). Using student evaluation of teaching in administrative control: the validity problem, Journal of Accounting Education, Vol. 6, pp. 1-14.

Ovando, M.N. (1989). An effective faculty development program: It can be done. Paper presented at the annual conference of the National Council of States on In service Education, San Antonio, Texas.

Pariseau, S.E. \& McDaniel, J.R. (1997). Assessing service quality in schools of business, International Journal of Quality \& Reliability Management, 14 (3), pp. 204-218

Patricia H. (2008). Pennsylvania State University. learningdesign@psu.edu. Retrieved from http://ets.tlt.psu.edu/learningdesign/syllabus

Peng, P.J. \& Samah, A.J.A. (2006). Measuring students' satisfaction for quality education in a e-learning university, Unitar E-Journal, 2 (1), pp. 11-21.

Peter J. Goodhew (2010). Teaching Engineering: All You Need to Know about Engineering Education. The Higher Education Academy.

Robert Coe, Cesare Aloisi, Steve Higgins \& Lee Elliot Major (2014). What Makes Great Teaching: Review of the Underpinning Research

Russell, M. (2005). Marketing Education: A review of service quality perceptions among international students. International Journal of Contemporary Hospitality Management, 17 (1), pp. 65-77.

Ryan, J.M. \& Harrison P.D. (1995). The relationship between individual instructional characteristics and the overall assessment of teaching effectiveness across different instructional contexts, Research in Higher Education, 36 (5), pp. 213-228.

Sang, H.B. (2007). The relationship between ISO 9000 participation and educational outcomes of schools, Quality Assurance in Education, 15 (3), pp. 251-270.

Sangeeta Sahney, D.K. Banwet \& S. Karunes (2012), "The Usefulness of Student Evaluations for Enhancing the
Effectiveness of Teaching of Financial Accounting Students at a South African University - South Africa"

Seldin, P. (1989). How colleges evaluate professors, American Association for Higher Education Bulletin, 41 (7), pp. 3-7.

Seldin, Peter (1993). How Colleges Evaluate Professors, 1983 v. 1993. POD Network Conference Materials. 110.

Serin, H. (2019) Student Evaluations of Teaching Effectiveness: An Instrument to Increase Teaching Quality in Higher Education. International Journal of Social Sciences \& Educational Studies, 5 (4). pp. 168-173

Shapiro, D. (1991). The effects of explanations on negative reactions to deceit, Administrative Quarterly, Vol. 36, pp. 614-30.

Shevlin, M., Banyard, P., Davies, M. \& Griffiths, M. (2000). The validity of student evaluation of teaching in higher education: love me, love my lectures? Assessment \& Evaluation in Higher Education, 25 (4), pp. 397-405.

Simpson, R. (1995). Uses and misuses of student evaluations of teaching effectiveness. Innovative Higher Education, 20 (1), 3-5.

Smith, F. (1995). Let's declare education a disaster and get on with our lives. Phi Delta Kappan, 76, 584-590.

Sohail, M.S. \& Shaikh, N.M. (2004). Quest for excellence in business education: a study of student impressions of service quality, The International Journal of Educational Management, 18 (1), pp. 58-65.

Soutar, G. \& McNeil, M. (1996). Measuring service quality in a tertiary institution. Journal of Educational Administration, 34 (1), 72-82.

Stratton, W.O. (1990) A model for the assessment of student evaluations of teaching, and the professional development of faculty, The Accounting Educators' Journal, Summer, pp. 77-101.

Strong, M., Gargani, J. \& Hacifazlioglu, O. (2011). Do We Know a Successful Teacher When We See One? Experiments in the Identification of Effective Teachers. Journal of Teacher Education, 62 (4), 367-382.

Toby, S. (1993). Class size and teaching evaluation or, the 'general chemistry effect revisited', Journal of Chemical Education, June, pp. 465-6.

Van der Merwe, D.C. (2012). The Usefulness of Student Evaluations for Enhancing the Effectiveness of Teaching of Financial Accounting Students at a South African University. In Accounting in Africa. Published online: 9 Mar 2015; 107-126.

Vernon, P.E. (1964). Personality Assessment: a critical survey (London, Methuen).

Wei Hong \& Shen Jiliang (2002). Study on Teaching Characteristics of Effective University Teacher. Journal of Southwest China Normal University (Humanities and Social Sciences Edition), (28) 33-36.

Whitworth, J.E., Price, B.A. \& Randall, C.H. (2002). Factors that affect college of business student opinion of teaching and learning, Journal of Education for Business, May/June, 282-289.

Yunker, P.J. \& Sterner, J. (1988). A Survey of Faculty Performance Evaluation in Accounting, Accounting Educators' Journal, Fall, pp. 63-71.

Yunker, P.J. \& Yunker, J.A. (2003). Are student evaluations of teaching valid? Evidence from an analytical business core course. Journal of Education for Business 78: 313-317. 